\title{
RELAÇÕES DE REPRESENTATIVIDADE E CONSUMO, A MULHER NEGRA E OS CABELOS CRESPOS NO YOUTUBE
}

\author{
RELATIONS BETWEEN REPRESENTATION AND CONSUMPTION, \\ BLACK WOMEN AND CURLY HAIR IN THE YOUTUBE \\ RELACIONES DE REPRESENTATIVIDAD Y CONSUMO, \\ LA MUJER NEGRA Y EL PELO RIZADO EN EL YOUTUBE
}

\section{ALINE TUSSET DE ROCCO'1}

\footnotetext{
${ }^{1}$ Mestra em Ciências Sociais pela Universidade do Vale do Rio dos Sinos (Unisinos). Integrou o Grupo de Pesquisa "Gênero e Raça em Contextos Africanos e Latino Americanos", Diretório de Pesquisa do CNPq (2015/02).

ORCID iD: https://orcid.org/0000-0003-3647-9204
}

\section{RESUMO}

Este estudo visa tratar sobre a representatividade da beleza negra, mais especificamente do cabelo crespo, levando em conta os estudos já realizados sobre a estética negra, assim como a agenda do feminismo negro. Através de uma etnografia digital em canais do Youtube que tratam sobre cabelos crespos, busca-se compreender a relação entre o consumo de produtos para o cabelo crespo, e como se dá a representatividade das mulheres negras em meios digitais e a construção de uma beleza negra. Por fim, visa-se analisar esta interação na tentativa de compreender dimensões da estética negra percebidas também como resistência política e social pelas mulheres negras.

Palavras-chave: Cabelo Crespo. Beleza Negra. Mulher Negra. Antropologia do Consumo. Mídias Digitais.

\section{ABSTRACT}

This study aims to treat about the representation of black beauty, more specifically curly hair, taking into account studies already conducted on black aesthetics, as well as the black feminism agenda. Through a digital ethnography on YouTube channels dealing with curly hair, we seek to understand the relationship between the consumption of products for curly hair, the representation of black women in digital media and the construction of a black 
beauty. Finally, it aims to analyze this interaction in the attempt to understand dimensions of black aesthetics perceived also as political and social resistance by black women.

Keywords: Anthropology of Consumption. Black Beauty. Curly Hair. Digital Media. Black women.

\section{RESUMEN}

Este estudio tiene como objetivo tratar la representatividad de la belleza negra, más específicamente de los cabellos rizados, teniendo en cuenta los estudios ya realizados sobre la estética negra, así como la agenda del feminismo negro. A través de una etnografía digital en los canales de Youtube que tratan sobre el cabello rizado, busca entender la relación entre el consumo de productos para el cabello rizado, y cómo las mujeres negras están representadas en los medios digitales y la construcción de la belleza negra. Por último, busca analizar esta interacción en un intento por comprender las dimensiones de la estética negra percibida también como resistencia política y social por parte de las mujeres negras.

Palabras clave: Antropología del consumo. Belleza Negra. Cabello rizado. Medios digitales. Mujer Negra

\section{INTRODUÇÃO}

Todos os dias ao ler jornais, ligar a televisão ou acessar a internet, o indivíduo é invadido por uma série de informações, imagens e propagandas. Apesar de escolher o conteúdo que lhe é interessante, as propagandas que intercalam estes conteúdos não são escolhidas. Estas propagandas parecem passar despercebidas pelo consciente, entretanto, elas fazem parte de um repertório imagético que compõe e constrói discursos que influenciam o modo de pensar e ver a realidade. Deste modo, um indivíduo ao ver-se representado em uma propaganda, comercial ou anúncio pode sentir-se contemplado pela sociedade, e parte de um retrato social que pode vir a incluí-lo como cidadão e consumidor.

O consumo, além de ser visto como marcador étnico, é uma forma de expressão de cidadania e status (SANSONE, 2000), também está ligado diretamente à construção de identidades contemporâneas (CANCLINI, 1996). Em contraponto, não ser representado 
pelas mídias ${ }^{1}$, é também ver seu corpo invisibilizado por um meio social que reflete e constrói discursos sociais. Logo, surge um problema quando propagandas são criadas de modo a reforçar relações de dominação e exclusão tornando inacessível a alguns indivíduos, como as mulheres negras, a representatividade social. Cabe ressaltar que os discursos da mídia não impactam somente o público-alvo, mas toda a sociedade que lê/assiste a comunicação de massa. Assim, faz-se relevante pensar sobre a representação da mulher negra e do cabelo crespo na mídia, principalmente em uma era onde a comunicação passa a ser criada também por quem a consome.

Desta maneira, busca-se aqui tratar sobre a representação da mulher negra pelo consumo através de um olhar das youtubers, que hoje criam e apresentam tendências para cabelos crespos e são, também, parte da representação da mulher negra na internet. Assim, esta pesquisa visa refletir sobre como a busca por uma naturalidade do cabelo crespo se apresenta como uma afirmação identitária da mulher negra e, também, como uma maneira de confrontar e resistir ao racismo e à inferiorização estética, social e política que lhes são impostos.

Deste modo, a grande questão que permeia este trabalho é: considerando os estudos e a agenda política das mulheres negras sobre a construção da beleza negra no Brasil, como as representações e interações em torno dos cabelos crespos dialoga com a produção de uma estética das mulheres negras? Para responder a esta pergunta de pesquisa, tracei um objetivo

\footnotetext{
${ }^{1} \mathrm{O}$ conceito de mídias não será aprofundado neste artigo, entretanto, vale sinalizar o que se compreende como mídias. Contextualiza-se, conforme Guazina (2007) que a origem de uso da palavra está relacionada ao mass media, a campanhas eleitorais e a estudos sobre o voto entre os anos 1920 e 1940 nos Estados Unidos, sendo assim sua abordagem era direcionada ao campo da Comunicação, mas também às Ciências Sociais. Com a consolidação da televisão, nos anos 1950, o foco das pesquisas de Comunicação foram redirecionados para este novo meio, e fazendo com que a própria área de conhecimento voltasse seu pensamento para compreender a televisão, rádio, imprensa e outros, não só como meios de comunicação, mas também em seus papéis como novas tecnologias. Com a chegada da internet, o leque de possibilidades aumentou ainda mais. Desta maneira, passou-se a estudar o conjunto de meios da indústria de comunicação, sendo esta a concepção de mídias utilizada neste artigo (GUAZINA, 2007). Seguindo este raciocínio, quando abordado o conceito de mídias digitais faz-se referência aos meios online de interação.
} 
geral que visa compreender como as representações e interações em torno do consumo estético direcionado ao cabelo crespo dialogam com a busca pelo reconhecimento da beleza de mulheres negras nas dimensões estética, política e social. A fim de atingir este objetivo, o artigo apresenta a contextualização do processo de busca das mulheres negras por reconhecimento nas dimensões estética, política e social; e a observação e análise sobre a importância da representatividade de mulheres negras e cabelos crespos nas mídias digitais, mais especificamente pela possibilidade de criação e interação de vídeos disponíveis no Youtube.

Assim, o intuito de fazer uma etnografia no site Youtube (mídia digital selecionada para este estudo) é o de compreender como as youtubers negras (como são chamadas as mulheres que fazem uso de canais do site Youtube) demonstram o uso dos produtos, dão dicas caseiras, e apresentam como o cabelo deve ser tratado para adquirir um determinado resultado estético. Buscou-se selecionar mulheres negras que tratam sobre a beleza negra, mas que também expressam um pouco da diversidade do debate acerca da beleza negra e da identidade negra.

Ao identificar como universo da pesquisa as mídias digitais, mais especificamente o Youtube, apresenta-se a bibliografia de apoio para a análise, sendo as concepções de etnografia de Geertz (1989), além de Miskolci (2013), La Rocca (2014), Cardoso (2009), que tratam especificamente do contexto das etnografias digitais. Assim, também é importante frisar que se utilizou o conceito de etnografia digital, e não netnografia, devido a esta ser a terminologia utilizada pelos autores que guiam os aspectos metodológicos desta pesquisa.

Segundo Geertz (1989), fazer uma etnografia é interpretar culturas, comportamentos e acontecimentos sociais, descrever os sistemas de signos. "Em etnografia, o dever da teoria é fornecer um vocabulário no qual possa ser expresso o que o ato simbólico tem a dizer sobre ele mesmo - isto é, sobre o papel da cultura na vida humana" (GEERTZ, 1989). Em suma, o autor apresenta a principal característica etnográfica: a interpretação do discurso social. 
$\mathrm{Na}$ antropologia contemporânea surgiram novas maneiras de etnografar e compreender uma cultura, através dos novos meios comunicacionais e da centralidade da imagem no século XXI. Esta nova possibilidade etnográfica, voltada às imagens, acaba por modificar os modos de escrita etnográfica, e também, a relação entre etnógrafo e etnografado. Logo, nascem novas percepções sobre a subjetividade com implicações políticas, éticas e estéticas.

Quanto ao uso da imagem como possibilidade na investigação contemporânea, para La Rocca (2014), a imagem é uma característica da sensibilidade contemporânea, forma típica da visualização do mundo atual. Hoje, nossos olhos são confrontados por novas tecnologias, pela passagem do analógico para o digital, e este novo olhar afeta não só a comunicação, mas também a cultura e o imaginário coletivo, impactando a maneira de pensar e ver o mundo social. Conforme o autor, nossos olhos são estimulados pelo mundo imagético de modo a formar um olhar capaz de compreender o real e suas facetas. Portanto, conhecer e compreender esse olhar é um modo de perceber a direção sociológica na qual a imagem é inserida, de modo a tornar-se cada vez mais central o papel da imagem no processo metodológico.

Quanto a essas imagens em meios digitais, Cardoso (2009) lembra que "a revolução informacional, proporcionada pela internet e pela tecnologia digital, tem sem dúvida um impacto profundo nas relações que estabelecemos com as imagens". Além do aumento dos aparelhos que proporcionam a experiência de fotografar e filmar, também nasceram os dispositivos que permitem, em minutos, o compartilhamento dessas imagens com milhares de pessoas na World Wide Web. Conforme o autor, a tecnologia digital possibilita a democratização na produção e compartilhamento de imagens, dando espaço para aqueles que antes eram meros espectadores produzirem informação e interagirem nos novos meios de comunicação.

Um dos grandes benefícios dos meios digitais, relatados pelo autor, é a possibilidade de comunidades de interesse que contrastam e tensionam os interesses mercadológicos 
(MISKOLCI, 2013, p. 20). Muitos que se sentiam antes isolados, agora podem fazer contato e romper ciclos de isolamento e discriminação. Assim, as mídias digitais podem fortalecer laços de afinidades, entrelaçando o político e o social de novas maneiras.

Diante da grande frequência de produção de imagens que estão por todo lugar, é certamente na internet que a grande maioria está agrupada, podendo ser encontradas através de portais de busca, mas, mais que isso, em sites que visam somente o compartilhamento de vídeos. Quando se pensa em compartilhamento de vídeos, o primeiro site que nos vem à mente certamente é o Youtube, sendo que este foi o primeiro a proporcionar a visualização e compartilhamento de vídeos, e, ainda hoje, mostra-se o mais popular do segmento. No Youtube, qualquer pessoa pode acessar, visualizar e postar vídeos, e a cada vez que acessa um vídeo, é defrontado com inúmeros links de outros vídeos que se relacionam de algum modo com o visualizado. Assim, pode-se dizer que o Youtube é uma comunidade virtual em torno do compartilhamento de imagens, proporcionando novos modelos de criação surgidos através das novas tecnologias digitais. Cardoso (2009) ainda chama atenção para outros aspectos usuais do Youtube:

Um fato que colabora para despertar o interesse ainda maior no site em relação à produção e ao compartilhamento de imagens é que ambos se dão simultaneamente. O mecanismo disponibilizado aos usuários, que os permite dar notas (de 1 a 5 estrelas) aos vídeos, e também comentá-los e postar respostas igualmente imagéticas, acaba se tornando parte do próprio processo de produção dos filmes, conferindo sentidos, estabelecendo fóruns de debate, enfim, ajudando a criar o texto final, num misto de imagens, ícones (as estrelas, por exemplo) e palavras. Em suma, o usuário é potencialmente, ao mesmo tempo, "produtor", "autor", "crítico", "espectador", colaborador" etc. Os vídeos aparecem como texto abertos, sujeitos a múltiplas interpretações e recriações interativas, adquirindo um caráter polifônico e também polissêmico. Ao entrar no site, as imagens perdem a autoria e passam a fazer parte de um domínio coletivo de autores, formado potencialmente por todos os usuários e efetivamente por todos os que interagiram diretamente com ele, através das notas ou dos comentários. Outros indicadores, como o número de pessoas que viram aquele vídeo e que o "adicionaram aos favoritos", também colaboram para a constante (re)criação daquelas imagens, embora de maneira mais indireta. As categorias autor e receptor perdem muito do sentido que 
habitualmente carregavam, assim como a imagem, que, ganha vida para além do momento em que foi captada, tornando-se um vídeo. Sua produção passa a ser, através da relação que se estabelece no site, aberta e interativa. (CARDOSO, 2009).

A partir do apresentado, propõe-se um olhar etnográfico em relação a essa forma de produção imagética, e como esta pode representar uma nova maneira de explorar e apresentar uma identidade e sua relação com o consumo e a representatividade negra. Deste modo, o foco não é apenas as imagens em si, mas toda a construção discursiva da youtuber, assim como as interações e a participação dos usuários que visualizam os vídeos e participam neste processo imagético criativo. Enfim, a interação proporcionada através das novas tecnologias digitais deve ser utilizada como fonte etnográfica, já que retrata o olhar daqueles que são os colaboradores da criação estética na sociedade do século XXI.

No Youtube, selecionou-se algumas dentre as diversas youtubers que tratam da questão estética do corpo negro e cabelo crespo. Durante dois anos de estudo, pesquisou-se em torno de 30 a 40 youtubers negras que abordam cuidados e manuseios com o cabelo crespo. Destas muitas mulheres negras interessadas em abordar o cabelo crespo, selecionouse oito. As youtubers foram escolhidas de acordo com critérios como: assunto de relevância para a pesquisa (tratam sobre o manuseio do cabelo crespo); reflexões sobre produtos relacionados à estética capilar; e atualização constante do canal.

Após a escolha das youtubers para esta pesquisa, definiu-se o período de etnografia, sendo este do início de cada canal (variando de uma youtuber para outra) até o final do mês de novembro de 2016. Assim, observou-se canais como o de Nátaly, que se iniciou recentemente, em julho de 2015; e canais com mais cinco anos como o de Maraisa, que teve seu primeiro vídeo postado em julho de 2011.

De modo a coletar os dados de maneira mais precisa, catalogou-se os vídeos com sua data de inclusão no Youtube, número e tema principal; além, é claro, das informações utilizadas na análise contendo as opiniões das youtubers, os comentários de seguidores e 
demais interações nos canais. Foram em torno de 1.200 vídeos catalogados, entretanto, nem todos os vídeos assistidos falavam especificamente sobre cabelos crespos, alguns vídeos eram sobre a vida pessoal, cuidados com o corpo, e outros; mas, de todo modo, contribuíram para esta etnografia e para a descrição de um perfil das mulheres selecionadas aqui.

Com relação ao perfil das mulheres negras selecionadas, as youtubers têm de 17 a 27 anos, sendo todas brasileiras e moradoras do país (com ressalva para Priscila que hoje reside em Londres). Tem-se aqui mulheres de São Paulo, Rio de Janeiro, Minas Gerais, Mato Grosso do Sul, Brasília e Bahia.

Após a visualização dos vídeos e coleta dos dados, unificou-se as percepções através de temas que foram percebidos como comuns para todas as youtubers. Dentre os temas recorrentes nas falas das youtubers, traz-se aqui um recorte que trata especificamente sobre o discurso em torno da representatividade da mulher negra e a visibilidade e construção da beleza negra. Logo, a partir do exemplificado, coletou-se e analisou-se os dados que foram transformados nos resultados que serão apresentados a seguir.

\section{COMUNICANDO ATRAVÉS DO CABELO}

Para iniciar, busca-se contextualizar a relevância do cabelo crespo como ferramenta estética e política para a mulher negra. O cabelo é parte de uma corporeidade ou performance corporal, estando sujeito às influências de grupos sociais. Para Quintão (2013), o cabelo é dotado de simbolismos que variam de uma cultura para outra, ou mesmo entre grupos da mesma cultura. Deste modo, como parte do corpo, o cabelo é também produto da sociedade em que está inserido o indivíduo, expressando suas intenções, desejos e diferenciando os indivíduos entre si na sociedade. Portanto, se cabelos carregam significados é possível pensar que cabelos lisos e crespos também diferem quanto à sua significação. Deste modo, o cabelo apresenta aspectos simbólicos e também de consumo, tornando-se ao mesmo tempo que uma performance corporal também uma performance econômica, já que é uma ferramenta de expressão social, mas também um objeto de consumo. 
De acordo com Gomes (2006), o cabelo crespo é uma expressão simbólica da identidade negra no Brasil, possibilitando, juntamente com o corpo, a construção social, cultural, política e ideológica conhecida como beleza negra. A identidade negra é, então, compreendida como um processo construído historicamente através do contato com o outro, em uma sociedade padecendo de racismo e do mito da democracia racial. Em seu livro Sem perder a raiz, a autora traz o fato de o cabelo crespo ser considerado "cabelo ruim" como uma expressão do racismo, e como a mudança do cabelo pode significar uma tentativa da mulher e do homem negros de saírem de um lugar de inferioridade a eles imposto. Assim, quando uma mulher negra assume seu cabelo natural, ela também pode estar assumindo sua identidade racial e confrontando o padrão estético.

Ainda conforme Gomes (2006), cabelo crespo para as mulheres negras é um sinal que imprime a marca da negritude no corpo, é a materialização da identidade negra. No Brasil, o cabelo crespo pode ser considerado um traço que comunica sobre as relações raciais, e pode ser pensado como um signo. Gomes (2006) afirma que assim como o mito da democracia racial, o estilo de cabelo pode ser uma maneira de encobrir dilemas relacionados a conflitos sociais e ao processo de construção de identidade negra. Também, o cabelo pode se apresentar como uma maneira de reconhecer as origens africanas, como resistência ao racismo e como um estilo de vida.

Como o cabelo pode ser visto como expressão do local do indivíduo em diferentes polos sociais e raciais, manifestações do ativismo feminista negro afirmam que determinadas manipulações com o cabelo podem ser atribuídas a uma tentativa de distanciamento da negritude (GOMES, 2006). Nessa perspectiva, alguns sujeitos vão apelar para a nãomodificação do cabelo crespo através de produtos químicos, a menos que este processo destaque a textura natural do cabelo, como por exemplo, os penteados afros.

Relembrando a importância da estética no âmbito político, Gomes (2006) comenta sobre como o cabelo afro e também os dreadlocks buscam pela originalidade africana. Logo, os dreadlocks foram incorporados ao ativismo negro de diversas partes do mundo como forma 
de afirmação da negritude e de um posicionamento político. A reivindicação proposta pelo movimento rastafári era muito próxima ao que havia surgido na década anterior com o black power, tratava-se da mesma concepção de que era possível ter um estilo negro que valorizasse o corpo negro livre de estereótipos.

Com os movimentos e manifestações negras verificamos também a ampliação do mercado direcionado à população negra. A publicidade se insere, então, para que a população negra possa se identificar e sentir-se representada nas imagens dos produtos que irão comprar. Para Coutinho (2011), mais do que um mercado que percebe a população negra como consumidora, foram os próprios consumidores negros e consumidoras negras que forçaram o mercado a se adequar a esta nova situação. Assim, o aumento da representação da população negra na mídia seria fruto da luta da própria população.

\section{MULHERES NEGRAS E A REPRESENTATIVIDADE MIDIÁTICA}

Conforme apresentado, as youtubers selecionadas nesta pesquisa têm idades entre 17 e 27 anos, e ao falarem da sua infância e da falta de representatividade nas mídias, reportamnos aos anos 1990 e até mesmo aos anos 2000. Assim, é muito recente no Brasil a inserção da população negra como consumidora, seja graças à ascensão social, seja graças à luta do movimento negro.

Débora lembra que durante a sua infância não se sentia representada, enquanto mulher negra, nem nos meios comunicacionais, nem pelo consumo. Ela afirma: "Nenhuma das princesas da Disney tinha o nosso perfil, todos eram tipo a Barbie”, ou seja, eram todas loiras, com cabelo liso, brancas, de olhos claros; logo, divergiam totalmente do que pode ser visto aqui como beleza negra, os cabelos crespos e o tom de pele escuro. Desta maneira, além de propagar um ideal de beleza relacionado à pele branca, também se perpetuava a ideia de que o cabelo belo era o cabelo liso, o cabelo comportado; reforçando a ideia de que o cabelo crespo e o volume eram feios, negando, assim, um lugar de beleza às mulheres que não possuem o cabelo conforme o padrão hegemônico. 
Nos dias atuais, percebe-se um início de inserção da mulher negra nas propagandas e no consumo brasileiro, principalmente no mercado estético. Entretanto, ainda que hoje existam empresas preocupadas em desenvolver produtos para cabelos crespos, e se apresentem propagandas sobre estes produtos na televisão e na Internet, Maraisa atenta para o fato de que os cabelos que são representados na mídia são os cabelos do tipo $3^{2}$ (cabelos crespos-cacheados), e dificilmente vemos mulheres negras de pele retinta com o cabelo tipo 4 (cabelos crespos) na televisão. Assim, para muitas mulheres que possuem o cabelo do tipo 4, como Maraisa, é difícil se identificar quando as propagandas, e até mesmo as novelas, apresentam apenas mulheres negras de pele menos retinta e com o cabelo com cachos definidos.

Acevedo e Nohara (2008) confirmam que a mídia no Brasil busca embranquecer a população negra, trazendo sempre traços de fenótipos arianos. Desse modo, pode-se ver um reflexo da ideologia do branqueamento do final do século XIX que permeia as relações sociais e a representatividade negra até os dias atuais. Através da visão de uma perpetuação da ideologia do embranquecimento, percebe-se o fato de que ter a pele mais clara e o cabelo mais definido é visto como um sinal de menor negritude, e logo, possibilita maior aceitação social.

Outra questão que circunda o debate da representatividade são os espaços onde são veiculadas estas propagandas. Nátaly problematiza a inserção da mulher negra em propagandas que visam apenas esta mulher como público-alvo, e recorda a pouca representatividade negra na televisão e em propagandas que são de veiculação nacional. Nátaly afirma em seu canal:

\footnotetext{
${ }^{2}$ Cabelo tipo 4 se refere ao cabelo crespo. Popularmente são 4 as categorias de textura capilar. Tipo 1, o cabelo liso. Tipo 2, o cabelo levemente ondulado. Tipo 3, o cabelo cacheado, ou cacheado/crespo,. Tipo 4, o cabelo crespo que não forma cachos.
} 
"É legal quando uma marca coloca pessoas negras, pessoas lésbicas, gays, gordos, em um comercial incrível, é muito legal. Mas não é tão legal quando esse comercial só é veiculado na Internet, não passa na TV, quando na TV ainda é aquele comercial que serve a tradicional família brasileira, como muitas pessoas criticaram na Internet sabiamente." (NERI, 2017).

Percebe-se, assim, que se por um lado algumas youtubers fazem uma crítica em relação à sociedade de consumo e aos meios de comunicação de massa, por outro, todas elas tratam da importância da inclusão da mulher negra através de espaços nos meios comunicacionais e também no consumo.

Nos discursos analisados por Acevedo e Nohara (2008), percebeu-se alguns fatores sobre a representação negra na mídia. Foram eles: pouca representatividade negra nas mídias; papéis subalternos e secundários delegados à população negra; retratos estigmatizados; personagens com imagens negativas relacionadas à pobreza ou violência; e desvalorização enquanto potencial de consumo, ligando a população negra a produtos de baixa qualidade e baratos. Em contrapartida, muitos entrevistados pelas autoras atentaram para um início de inserção da população negra para além deste lugar estigmatizado que lhe era atribuído. Algumas empresas começam a perceber o potencial de consumo da população negra, sendo este também um reflexo de políticas públicas que inseriram a população negra no ensino superior e no mercado de trabalho, refletindo, então, também na representatividade midiática.

Assim, apesar da crítica à baixa representatividade negra, Acevedo e Nohara (2008) também trazem estudos recentes dos anos 2000, como o de Silva (2001) que tem mostrado uma maior representatividade e diversidade negra nas mídias. Algumas das mudanças positivas encontradas foram: diminuição de papéis subalternos, crianças negras representadas nas escolas ou em atividades de lazer, maior interação entre etnias, personagem negro como central, e não associação entre animais e negritude. No entanto, apesar das mudanças apresentadas, a população negra ainda é menos representada em comparação com a sua real porcentagem na população brasileira. 
Destaca-se também que a busca não é apenas pela representatividade estética, já que esta esfera se reflete também na inclusão política e econômica da população negra. Nátaly afirma: "A gente não quer representatividade, a gente quer proporcionalidade. Ou seja, somos 50 , mais de $50 \%$ da população, então essa $50 \%$ da população tem que estar na TV, tem que estar na revista." (NERI, 2017).

Para além da representatividade na grande mídia, também é possível abordar a representatividade em meios como a internet. Acredita-se que um dos papéis mais importantes de uma youtuber negra que aborda temas relacionados à estética e à beleza negra é justamente dar visibilidade ao que é invisibilizado pela mídia convencional. Pode-se, então, perceber a internet como um novo espaço que possibilita novas formas de pertencimento, afetando processos sociais e o próprio consumo.

Além disso, conforme muitas das seguidoras lembram, as youtubers negras são um exemplo de beleza negra, de autoestima e coragem; e ao se exporem no canal também se transformam na representação da mulher negra na $W e b$, sendo então inspiração para muitas outras mulheres que não conseguem se enxergar na televisão, ou nas propagandas tradicionais. Por exemplo, no canal de Ana Lídia Lopes lê-se um destes depoimentos que exprimem a importância da representatividade negra:

“Ana, você não sabe o tanto que esse vídeo me ajudou, eu me sinto tão feia tendo cabelo curto e cacheado, porque para a sociedade comprido e liso é o que eles acham bonito, e quase todos os dias eu ouço críticas e isso me deixa muito muito para baixo ao ponto de chorar muito, e vendo seu vídeo eu percebi muita coisa aprendi muita coisa , obrigado.".

Outro comentário muito interessante foi deixado no canal de Nátaly Néri.

"Não dá pra esquecer o primeiro lugar que me senti representada por ser mulher, por ser negra e não corresponder aos padrões impostos pela sociedade. Você não imagina o quanto o seu conteúdo é capaz de transformar vidas. Se hoje eu sei um pouco da história do meu povo, dos meus 
descendentes, do meu cabelo, do meu tom é por que você proporcionou isso a mim e a tantos esses que te seguem!"

Assim, diversas mulheres negras relatam sua identificação com as youtubers, da mesma maneira que agradecem e enaltecem o conteúdo por elas apresentado. Para além do simples aprendizado em relação aos cuidados com seus cabelos, as seguidoras enaltecem a possibilidade de aprendizado sobre sua negritude. Ao mesmo tempo que se pode ver diversas mulheres negras agradecendo pela representatividade negra no Youtube, encontramos pessoas brancas que assistem aos vídeos e interagem positivamente.

Um ponto importante a ser levantado aqui, é de como essa rede de representatividade se expande e inspira outras mulheres. Dani Azevedo lembra que há 4 anos quando tomou a decisão de deixar seu cabelo novamente natural, inspirou-se em outra youtuber para aprender sobre cuidados e manuseios, além de ganhar coragem para encarar esta nova fase. Diferente de Dani, Débora afirma que quando resolveu deixar o cabelo com seu aspecto natural, esta foi uma decisão "de dentro pra fora". Contudo, Débora utilizou como referências os cabelos de cantoras africanas de que é fã, já que encontrou apenas uma blogueira que tratava sobre cabelos crespos e cacheados naquela época. Hoje, Débora vê uma maior expansão das youtubers e demais influenciadoras digitais negras (blogueiras, e outras mulheres negras que criam conteúdo para mídias digitais), e inclusive, em um de seus vídeos apresenta "negras para se inspirar no Instagram".

Assim como Débora, Nátaly também não se via representada no Youtube quando iniciou sua transição capilar, ela lembra que os tutoriais na internet eram majoritariamente para meninas brancas de cabelos lisos. Este foi um dos motivos que levou Nátaly a fazer o canal, a trazer consciência sobre a negritude, mas também para ajudar a autoestima das mulheres negras através de dicas para cabelos e maquiagens.

Em sequência, Débora afirma a importância das youtubers como inspiração de beleza negra para as meninas mais jovens que estão passando por fases de negação do cabelo crespo, ou mesmo para mulheres que querem retornar ao cabelo natural. Através da fala de Nátaly 
em seu canal "Afros e Afins", confirma-se a visão de muitas youtubers quanto à importância da sua presença online.

“Aí eu fiquei pensando: nossa, se as pessoas que eu assistia, as meninas negras que eram poucas na época, tivessem pegado um momento, por exemplo, pra falar sobre negritude, pra falar sobre racismo, pra falar que o fato de eu me odiar, de eu não gostar de mim mesma não era culpa minha, mas era culpa do mundo a minha volta, de uma estrutura que fazia com que eu me odiasse. Teria sido muito mais fácil, eu pensava. E aí eu decidi criar o canal, justamente pra falar com as meninas mais jovens, as meninas que, no caso, pudessem ser eu naquela época na Internet.” (NERI, 2017).

Uma das seguidoras de Ana Lídia, entretanto, atenta para o fato de que a representatividade negra no Youtube ainda é de mulheres negras jovens, e ela, enquanto uma mulher negra de mais idade, não se vê representada. Isso se dá muito devido à relação da juventude com os novos meios de comunicação como a internet. Por ter se popularizado no Brasil nos anos 1990 e 2000, fica claro que o público que mais tem conhecimento e acesso a canais como Youtube era composto inicialmente por jovens com menos de 30 anos, já que conforme atentou Miskolci (2013), os nascidos na década de 1970 já eram adultos socializados quando a internet se tornou acessível à população em geral. Entretanto, a observação da seguidora é extremamente válida para pensarmos sobre quais as mulheres negras que estão sendo representadas na internet.

Por fim, vale frisar que segundo Acevedo e Nohara (2008) a maior representatividade da população negra nas mídias também está relacionada a novas políticas públicas de inclusão. Sejam políticas públicas de inclusão de representatividade nas mídias, sejam políticas públicas que proporcionem uma integração à população negra no mercado de trabalho, e principalmente, ao acesso ao ensino superior. Logo, ressalta-se que o aumento da população negra de classe média também vem a contribuir para uma maior representação da população negra no país. 


\section{CONSIDERAÇÕES FINAIS}

Neste estudo, buscou-se compreender a relação entre as novas mercadorias estéticas e a representação negra direcionados ao cabelo crespo, de maneira a levar em conta sua interação com a busca da mulher negra pelo reconhecimento de uma beleza negra em dimensão estética, mas também política e social.

Deste modo, tratou-se neste estudo a não representatividade da mulher negra na mídia e seu reflexo na exclusão da população negra tanto estética, quanto política e social. Assim, conforme o discurso das youtubers, a abertura de um mercado estético que leve em consideração as necessidades e apelos da população negra pode ser vista, desta maneira, como uma forma de incluir esta população tanto nas esferas de consumo, como também na esfera social.

Ao decidir por uma etnografia digital, enfatizou-se, também, a possibilidade da construção e afirmação da estética da mulher negra através das novas mídias digitais, como o Youtube. Ademais, os canais do Youtube podem ser vistos como espaços de afirmação da negritude que proporcionam visibilidade à beleza negra e ao cabelo crespo e seus penteados. Também fica evidente que o acesso à informação e aos meios digitais também proporciona uma maior facilidade para a mulher negra que deseja redescobrir os seus fios crespos.

Além disso, demonstram-se aspectos sobre a representatividade da mulher negra nas mídias e sua influência tanto na aquisição do produto quanto na relação emocional das mulheres negras com sua autoestima. Falar sobre representatividade é tratar do direito de as mulheres negras verem-se e serem vistas também como belas.

Para além da representatividade da mulher negra, sugere-se que as novas possibilidades de consumo no mercado estético também acabam por proporcionar que a sociedade repense sobre os estereótipos ligados ao corpo negro. De modo a trazer a consumidora negra para perto de seus produtos, as empresas percebem a necessidade de modificar sua representação da população negra, dando então oportunidade para as mulheres negras serem representadas na mídia para além dos estereótipos usuais. 
Se a mídia tem capacidade para expor e reforçar relações de dominação e exclusão da população negra, ligando a mulher negra a estereótipos, esta mídia também tem aptidão para reproduzir discursos que impactem positivamente sobre as experiências das mulheres negras. Seja através da inclusão através do consumo, seja pelo sentimento de pertença à sociedade e à cidadania, seja pela representatividade midiática, a estética negra não pode ser deslocada das suas interações sociais, políticas e econômicas. Tanto no campo das pesquisas, quanto no consumo, é preciso afirmar a visibilidade do corpo negro, assim como perceber que este vai além da dimensão estética, também explorando debates sociais e políticos.

\section{REFERÊNCIAS}

ACEVEDO, Claudia Rosa; NOHARA, Jouliana Jordan. Interpretaçőes sobre os Retratos dos Afro-descendentes na Mídia de Massa. RAC, Curitiba, Edição especial, p. 119-146, 2008.

AZEVEDO, Dani, Youtube. Disponível em: $<$ https://www.youtube.com/channel/UCNnmqjN7_8F4p6Sfa_D1uyQ> Acesso em: 30 mar. 2017.

CANCLINI, Néstor García. Consumidores e cidadãos: conflitos multiculturais da globalização. In: Consumidores e cidadãos: conflitos multiculturais da globalização. Rio de Janeiro: Editora UFRJ, 1996.

CARDOSO, Bruno de Vasconcelos. Voyeurismo digital: representação e (re)produção imagética do outro no ciberespaço. In: GONÇALVES, Marco. A; HEAD, Scott (2009), Devires Imagéticos-A Etnografia, o Outro e suas Imagens. 2009.

COUTINHO, Cassi Ladi Reis. A Estética e o mercado produtor-consumidor de beleza e cultura. XXVI Simpósio Nacional de História, São Paulo, 2011.

FIDELIS, Maraisa. Youtube. Disponível em: $<$ https://www.youtube.com/channel/UCluNp2nZNc_FJ4KUBj6Rxcg $>$ Acesso em: 30 mar. 2017.

GEERTZ, Clifford. Uma descrição densa: por uma teoria interpretativa da cultura. In: . A interpretação das culturas. Rio de Janeiro: LTC, 1989. 
GOMES, Nilma Lino. Sem perder a raiz: corpo e cabelo como símbolos da identidade negra. Autêntica, 2006.

GUAZINA, Liziane. O conceito de mídia na comunicação e na ciência política: desafios interdisciplinares. Revista Debates, v. 1, n. 1, p. 49, 2007.

LA ROCCA, Fabio. A reprodutibilidade tecnológica da imagem. TESSITURAS: Revista de Antropologia e Arqueologia, v. 2, n. 2, p. 114, 2014.

LIMA, Eva. Youtube. Disponível em: <https://www.youtube.com/channel/UCpHXkd9LphwnsD6y650KyA> Acesso em: 30 mar. 2017.

LOPES, Ana Lídia. Youtube. Disponível em: $<$ https://www.youtube.com/channel/UCUDk9RgdFKmTcty4cfUDcXg> Acesso em: 30 mar. 2017.

LUZ, Débora. Youtube. Disponível em: $<$ https:/www.youtube.com/c/D\%C3\%A9boraLuz/videos> Acesso em: 30 mar. 2017.

MACEDO, Ny. Youtube. Disponível em: <https://www.youtube.com/user/nymacedo> Acesso em: 30 mar. 2017.

MISKOLCI, Richard. Novas conexões: notas teórico-metodológicas para pesquisas sobre o uso de mídias digitais. Revista Cronos, v. 12, n. 2, 2013.

NERI, Nátaly. Youtube. Disponível em: <https://www.youtube.com/channel/ UCjivwB8MrrGCMlIuoSdkrQg>. Acesso em 30. mar. 2017.

QUINTÃO, Adriana Maria Penna. O que ela tem na cabeça? Um estudo sobre o cabelo como performance identitária. Dissertação. Universidade Federal Fluminense, Instituto de Ciências Humanas e Filosofia, Departamento de Antropologia, 2013.

SANSONE, Livio. Os objetos da identidade negra: consumo, mercantilização, globalização e a criação de culturas negras no Brasil. Mana, v. 6, n. 1, p. 87-119, 2000.

SILVA, Ana Célia da. As transformações da representação social do negro no livro didático e seus determinantes. 2001. Tese de doutorado. Universidade Federal da Bahia, Salvador, 2001. 


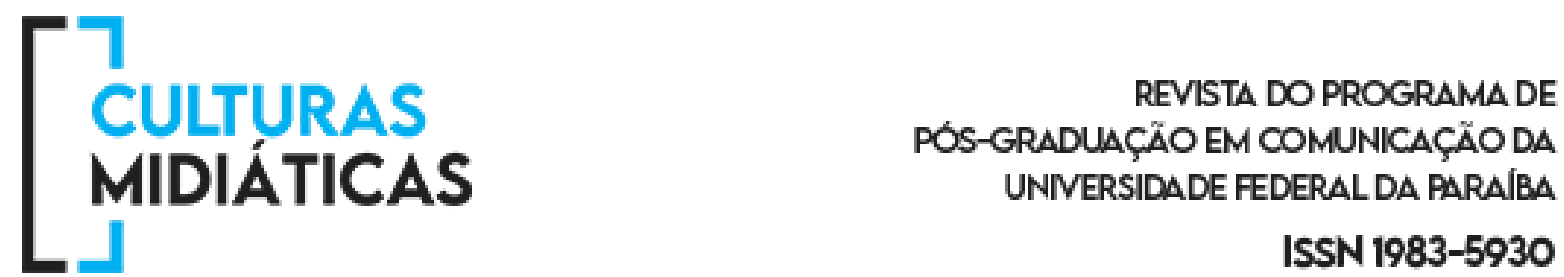

SILVA, Priscila. Youtube. Disponível em: $<$ https://www.youtube.com/user/Priddm/videos>. Acesso em 30. mar. 2017. 